\title{
Regulamento do Ensino Primário e Normal do Estado do Rio Grande do Norte
}

\section{(Aprovado pelo Decreto n ${ }^{\circ} 3.590$, de $1^{\circ}$ de fevereiro de 1960)}

No governo de Dinarte de Medeiros Mariz e José Augusto Varela (1956-196 1) foi empreendida uma reforma educacional ordenada pela Lei $n^{\circ}$ 2.171, de 6 de dezembro de 1957, preconizando organizar e fixar as bases da Educação Primária e da Formação do Magistério no Estado do Rio Grande do Norte. Passados três anos da aprovação dessa reforma educacional de 1957, o governador Dinarte de Medeiros Mariz sancionou (Decreto n 3.590, de $1^{\circ}$ de fevereiro de 1960), o Regulamento do Ensino Primário e Normal do Estado do Rio Grande do Norte cujo Título I é o da Obrigação Escolar que reafirmava a obrigatoriedade do ensino primário para todas as crianças de 7 a 13 anos, e o dever do Estado em assegurar os meios e as condições para $\circ$ cumprimento dessa obrigação. Para o cumprimento da obrigatoriedade esco269 lar, o Estado ampliaria a rede escolar e o número de professores primários, em preparação com as necessidades devidamente recenseadas. Em face da relevância desse Regulamento de 1960 para História da Educação do Rio Grande do Norte é que se publica nesta Seção de Documento.

Marta Maria de Araújo Editora Responsável da Revista Educação em Questão 


\title{
Regulamento do Ensino Primário e Normal do Estado do Rio Grande do Norte
}

\author{
(Aprovado pelo Decreto $n^{\circ} 3.590$, de $1^{\circ}$ de fevereiro de 1960)
}

\section{Título I - Da Obrigação Escolar}

Art. $1^{\circ}$ - Sendo obrigatória o ensino para todas as crianças de 7 a 13 anos, deverá o Estado assegurar os meios e as condições para o cumprimento dessa obrigação.

$\S 1^{\circ}$ - Com esse objetivo, ampliará a sua rede escolar e o número de professores primários, em preparação com as necessidades, devidamente recenseadas. $\S 2^{\circ}$ - Sendo a educação primária a única acessível à grande maioria da população, caberá ao Governo do Estado:

I - Atribuir-he absoluta prioridade, em relação aos outros graus de ensino, devendo para tornar efetiva essa disposição, concentrar nela, de forma preferencial, os seus recursos.

II - Velar pela sua qualidade, mediante a adequada formação profissional dos professores.

Art. $2^{\circ}$ - $\bigcirc$ período de escolaridade obrigatória destinado a assegurar as condições adequadas de desenvolvimento da criança, de sua integridade social, e iniciação em atividades de trabalho abrangerá todos os alunos que não prosseguem os seus estudos em curso de nível médio. Os dois últimos anos desse período, que constituem os cursos complementar, se destinam igualmente a cobrir o intervalo entre a idade terminal do curso primário ( 11 anos), e idade legal de trabalho ( 14 anos). $\bigcirc$ período de escola obrigatória abrange a educação primária a educação complementar, este último podendo ser substituído por outro curso de nível médio.

\section{Título II - Da Educação Elementar}

Capítulo I - Dos objetivos

Art. $3^{\circ}$ - A educação primária terá os seguintes objetivos: 
a) aquisição dos instrumentos básicos de expressão de raciocínio: ler, escrever e contar; b) formação moral e desenvolvimento das aptidões intelectuais, da sensibilidade e da imaginação;

c) conhecimento de meio, estimulando o hábito de observação e da pesquisa pessoal, e o interesse pelos assuntos mais ligados à experiência do aluno, à sua região e ao país;

d) estimular o gosto pelo trabalho e pelas atividades úteis, inclusive pela iniciação em técnicas que correspondem às necessidades correntes;

$\S$ Único - Os métodos a serem utilizados, na realização dessas finalidades, deverão fundar-se nos interesses e atividades espontâneas da criança, e no caráter objetivo e prático do ensino.

Capítulo II - Da Estrutura

Art. $4^{\circ}$ - A Educação Elementar compreende:

a) o Jardim de Infância, para crianças no período pré-escolar;

b) o Curso Primário, para crianças de 7 a 11 anos.

Art. $5^{\circ}$ - Os jardins de Infância público atenderão de preferência, as crianças

271 cujas as mães trabalhem.

Art. $6^{\circ}$ - Promoverá o Estado a expansão da educação pré-primária, mas, somente, depois de haver número suficiente de escolas primárias com a duração do dia escolar estabelecida neste Regulamento.

Art. $7^{\circ}-\bigcirc$ curso primário compreenderá dois ciclos: o primeiro de três anos e o segundo de dois anos.

$\S$ Único - As crianças que, após o segundo ano de estudos, revelarem perfeito domínio do programa do primeiro ciclo, serão dispensadas do $3^{\circ}$ ano deste ciclo.

Capítulo III - Da Articulação dos Cursos

Art. $8^{\circ}$ - Far-se-á a articulação;

a) de Jardim de Infância com o primeiro ciclo de curso primário, para as crianças de 7 anos e, também, para as de 6 que se mostrarem capazes de aprendizagem escolar;

b) do primeiro com o segundo ciclo de curso primário; 
c) de segundo ofício de curso primário com o curso complementar e os cursos de nível médio, em geral.

Capítulo IV - Dos Estabelecimentos de Ensino Primário

Art. $9^{\circ}$ - Os estabelecimentos de ensino primário poderão ser públicos ou particulares, conforme dependem ou não de poder público e por ele sejam mantidos.

Art. $10^{\circ}$ - Empenhar-se-á o Estado no sentido de instalar as escolas primárias em prédio próprio, e impedirá rigorosamente nas escolas atividades estranhas à educação.

Art. $11^{\circ}$ - As escolas isoladas terão local para bibliotecas e reunião dos pais. Art. $12^{\circ}$ - Os prédios escolares, construídos segundo normas corretas de orientação e devidamente equipados, deverão apresentar condições adequadas quanto à cubagem por aluno, serviços de abastecimento d'agua, instalações sanitárias e outros requisitos higiênicos indispensáveis.

Capítulo V - Do Trabalho Escolar e sua Direção

Art. $13^{\circ}-\bigcirc$ ano escolar do Jardim de Infância, terá a mesma duração que o curso primário.

Art. $14^{\circ}-\bigcirc$ número de anos que terá o Jardim de Infância variável de um a três, aumentará à proporção que forem atendidas as necessidades da educação primária.

Art. $15^{\circ}$ - $\bigcirc$ primeiro ciclo primário terá 24 horas de duração, digo, trabalho semanal e o segundo de 36 horas.

$\S$ Único - Enquanto as instalações existentes não permitirem o regime estabelecido neste artigo, será assegurado aos alunos um mínimo de 24 horas nas turmas comuns e 21 horas nas de aceleração e nas especiais.

Art. $16^{\circ}$ - Afim de ser evitado qualquer perturbação nas atividades das escolas primárias, será proibido o funcionamento nela, de cursos que the sejam estranhos, e tornados sem efeito as concessões existentes.

Art. $17^{\circ}$ - Para se desobrigarem, convenientemente, de suas tarefas, inclusive de preparação do material escolar, antes das aulas, permanecerão os professores na escola pelo menos durante trinta horas semanais. 
$\S$ Único - Os professores de classe de aceleração e de classes especiais completarão o tempo regulamentar, prestando assistência individual aos alunos.

Art. $18^{\circ}$ - $\bigcirc$ ano letivo terá 250 dias e será só as circunstâncias de força maior, de excepcional gravidade, poderão determinar a sua redução.

$\S$ Único - Em qualquer hipótese terá concluído o ano letivo somente o aluno que contar 200 dias escolares.

Art. $19^{\circ}$ - Os períodos de férias no meio e no fim do ano letivo de 10 a 15 dias e de dois meses respectivamente, serão fixados segundo as condições de trabalho e o clima de cada região.

Capítulo VI - Da Matrícula e da Organização das Classes

Art. $20^{\circ}$ - A matrícula nas escolas primarias será feita no fim do ano letivo para o ano seguinte, admitindo-se, todavia, a possibilidade de conseguir o aluno, durante as férias, condições para a sua reclassificação. Também em caráter excepcional poderão ser feitas novas matrículas, no início do ano letivo.

$273 \S$ Único - Tendo em vista o disposto neste artigo, cada escola procederá no fim do ano letivo à verificação das matrículas e serem renovadas e das vagas que ocorrerão em cada classe.

Art. $21^{\circ}$ - Obedecendo a organização das classes ao critério de idade cronológica dos alunos, serão, matriculados na $1^{a}$ série os de 6 a 7 anos, e excepcionalmente os de 8 anos; na $2^{a}$, os de 8 a 9 ; na $3^{a}$, os de 9 e 10; os de 10 e 11; na $5^{a}$, os de 11 e 12 na $6^{a}$, os de 13 e 14 .

$\S$ Único - $\bigcirc$ critério de organização de classe, estabelecido neste artigo, deverá ser seguido, com grande cautela e somente, na zona urbana, quando se apresentarem condições adequadas para a sua implantação.

Art. $22^{\circ}$ - Nas escolas onde houver disponibilidade de lugares, serão constituídos classes de aceleração que sirvam a vários estabelecimentos de ensino, agrupando todos os alunos que neste, não apresentarem condições de ingressar na série correspondente a sua idade.

$\S 1^{\circ}$ - As classes de aceleração deverão funcionar no curso vespertino, sempre que for possível, digo, inevitável o regime de três turnos, com programa escolar reduzido as matérias básicas do currículo. 
$\S 2^{\circ}$ - Completar-se-á a educação desses alunos com atividades de trabalho em oficinas de artes industriais.

Art. $23^{\circ}$ - A fim de promover a distribuição sistemática dos alunos pelas oficinas e classes de aceleração mais próximos do local onde residem, far-se-á o recenseamento dos alunos incluídos na categoria prevista no artigo anterior e o seu zoneamento.

$\S 1^{\circ}$ - A Caixa Escolar ou outras instituições congêneras com a cooperação da Secretaria de Educação, concederá auxílio para o transporte de crianças sem recursos, residentes a mais de dois quilômetros da escola. Igual finalidade poderá ter lucro obtido nas oficinas de artes industriais, além de outras como merenda, uniformes, excursões.

Art. $24^{\circ}$ - Tendo em vista o melhor rendimento escolar, serão constituídas em cada classe, sempre que possível, turmas de alunos fortes e médios, e médios e fracos, ou seja apresentando só dois níveis de aproveitamento.

Art. $25^{\circ}$ - As crianças de mais de 9 anos que procurarem a escola sem nenhuma escolaridade, constituirão turmas especiais de aceleração.

Capítulo VII - Do Currículo

Art. $26^{\circ}$ - As atividades de Jardim de Infância visam a despertar e desenvolver livremente as aptidões das crianças.

Art. $27^{\circ}$ - $\bigcirc$ currículo primário incluirá, basicamente, Linguagem, Matemática, Estudos Sociais, Ciências Naturais, Recreação e Jogos, Atividades de Trabalho e Atividades Artísticas.

$\S$ Único - $\bigcirc$ aprendizado de Estudos Sociais e de Ciências Naturais deverão basear-se no estudo do meio natural e humano, mediante a observação direta e a valorização da experiência e da pesquisa pessoal do aluno.

Art. $28^{\circ}$ - Haverá programa próprio para as classes de aceleração, os quais utilizarão, para efeito de orientação do ensino a experiência já adquirida pelo aluno e as suas condições da maturidade.

$\S$ Único - Os programas referidos neste artigo serão acentuadamente práticos, incluindo, como atividade preponderante, ao lado da formação de atitudes morais e sociais, o domínio das técnicas de leitura e escrita conhecimentos práticos de Matemática e o estudo do meio. 
Art. $29^{\circ}$ - A elaboração dos programas constituirá encargo do COPE, que procurará adaptá-lo às condições educacionais concretas do Estado, e, ao mesmo tempo, submetê-lo sempre que for oportuno às revisões e melhoramentos inspirados nas experiências realizadas nestes e noutros centro educacionais. $\S$ Único - Para este fim, contará o COPE, com a cooperação dos Orientadores Educacionais e Diretores Escolares, além de outras pessoas ligadas ao problema.

Art. $30^{\circ}$ - Todos os professores deverão receber da Secretaria de Educação e Cultura, esclarecimentos sobre os programas escolares e seus objetivos. A orientação sobre os métodos e execução, que também o acompanhará deverá restringir-se só ao indispensável, sem prejuízo da autonomia do professor.

Art. $31^{\circ}$ - Os programas serão inflexíveis, adaptando-se as diferenças individuais, às peculiaridades do meio e ao tempo de escolaridade dos alunos, devendo, igualmente, ser enriquecidos na medida dos recursos humanos e materiais disponíveis.

Art. $32^{\circ}$ - Os programas de ensino primário serão devidamente estudados nos cursos de formação de professores, particularmente os pontos em relação às 275 quais apresentam maiores dificuldades práticas.

Capítulo VIII - Da Promoção e da Avaliação de Rendimento Escolar

Art. $33^{\circ}$ - A promoção será flexível, segundo o critério de grupos de idade e de aproveitamento escolar.

$\S$ Único - Constituirão exceção as crianças que por motivo de imaturidade, serão reunidos às de idade imediatamente inferior.

Art. $34^{\circ}$ - Caberá o professor decidir sobre a promoção do aluno, mediante - julgamento do conjunto de suas atividades escolares, durante o ano letivo, levando em conta igualmente o tipo de classe a que pertencia.

Art. $35^{\circ}$ - No final do ano escolar, julgando o professor não ter elementos suficientes para decidir da promoção de certos alunos, valer-se-á, como recursos aos vários níveis, digo, recurso subsidiário, de provas laboradas pelo aluno digo, pelo COPE, correspondentes aos vários níveis de aproveitamento escolar. $\S 1^{\circ}$ - As provas previstas neste artigo poderão igualmente ser aplicadas, com preferência no fim do ano letivo, para fins de pesquisa educacional. 
$\S 2^{\circ}$ - Para essas provas serão reservadas, no máximo, seis horas de trabalho, por aluno, distribuídas em dois ou três dias.

Art. $36^{\circ}-$ A dispensa do $3^{\circ}$ ano do $1^{\circ}$ ciclo elementar nos termos do artigo VII, parágrafo único, assim como a concessão do certificado, de ensino primário, ficarão condicionados às exigências que parecem necessárias à Secretaria de Educação e Cultura, inclusive a realização de provas, atendendo-se em qualquer hipótese, ao julgamento do professor e à frequência escolar.

Art. $37^{\circ}$ - Os alunos que não obtiverem promoção na época regulamentar, por razões excepcionais de ordem psicológica ou de saúde, poderão consegui-las nos três primeiros meses do ano letivo com a assistência, dada individualmente, pelos professores da classe.

Art. $38^{\circ}$ - A educação da criança, do ponto de vista metodológico, obedecerá as seguintes características:

a) a mais completa integração entre as suas várias formas de atividade, articulando convenientemente, o conhecimento teórico e a experiência prática;

b) compreensão prática de coisas, fatos e técnicas ligadas a vida corrente, em vista da integração social;

c) a vida escolar será organizada com a mais ampla diversificação de atividades, de modo que todas as aptidões da criança, sejam valorizadas e tenham as mesmas oportunidades de revelar-se e expandir-se;

d) aplicação de métodos baseados, convenientemente, nos interesses e atividades espontâneas da criança.

Art. $39^{\circ}$ - Empenhar-se-á a Secretaria da Educação e Cultura em proporcionar eficiente assistência ao trabalho do professor através de cursos, seminários, estágios, reuniões, etc., e da atuação de Orientadores Educacionais e Diretores da Escola.

Art. $40^{\circ}$ - São condições para a nomeação do Orientador Educacional:

a) classificação em curso especializado;

b) cinco anos de eficiente exercício do magistério primário;

c) estágio probatório de um ano.

Capítulo IX - Dos serviços de assistência à escola e de sua relação com a comunidade 
Art. $41^{\circ}$ - Organizará a Secretaria de Educação e Cultura na medida em que tiver pessoal habilitado para promovê-los os seguintes serviços de assistências à escola: Serviço Médico, Serviço Dentário, Serviço de Assistência Social aos alunos e seus pais.

Art. $42^{\circ}$ - Caberá à escola incrementar a criação dos serviços assistenciais próprios, aprovados pela Secretaria de Educação e Cultura, como a Caixa Escolar, a Merenda Escolar, o Fundo de Assistência aos alunos etc.

Art. $43^{\circ}$ - Atentos os professores a necessidade de integração de escola à comunidade e ao fato de que o rendimento escolar depende, em grande parte, da promoção cultural geral, cabe-thes:

a) criar Associação de Pais e Mestres e fomentar de todas as formas, a aproximação entre os pais e a escola, tendo em vista os problemas ligados à vida escolar e a vida local;

b) proporcionar aos pais e à comunidade os meios de informação e cultura, como bibliotecas, conferências, músicas, teatro, revistas, além de outros.

$\S$ Único - Nas reuniões de pais e mestres e nas demais atividades sociais da escola se evitará, rigorosamente, qualquer sentido político-partidário.

\section{Título III - Dos Estabelecimentos de Ensino Primário}

Art. $44^{\circ}$ - Haverá os seguintes tipos de estabelecimentos de ensino primário;

a) Escola Isolada, com turma de alunos e um professor;

b) Escolas Reunidas, com o número de turmas que poderá variar de duas a quatro e igual número de professores;

c) Grupos Escolares, cinco turmas, pelo menos, e igual número de professores de classe, aos quais se reunirão, quando possível, professores especializados em atividades artísticas e de trabalho e em educação física, além de outros, que tem por finalidade o enriquecimento do currículo.

\section{Título IV - Do Curso Complementar}

Art. $45^{\circ}$ - $\bigcirc$ Curso Complementar se destina aos menores de 11 a 13 anos, que não ingressarem em outro curso do nível médio. 
Art. $46^{\circ}$ - Tendo os mesmos objetivos gerais da educação primária, a Educação Complementar visa aperfeiçoar a educação fundamental com elemento de cultura e iniciação nas técnicas de mais correntes de trabalho, Idesse conjunto devendo resultar de um mínimo de aptidão para o exercício de atividades úteis).

Art. $47^{\circ}$ - Abrangendo a educação complementar problemas novos, relacionados com a formação do professor e a estruturação do curso, e a sua articulação com outros cursos do nível médio, deverá o Governo do Estado, oportunamente, baixar decreto com a sua regulamentação.

\section{Título V - Do Ensino Supletivo}

Art. $48^{\circ}$ - No curso supletivo receberão os adolescentes e adultos que dele carecerem, a educação de base, ministrado de forma quanto possível prática e articulada com as atividades profissionais.

$\S 1^{\circ}$ - Os cursos supletivos, funcionará normalmente, no horário noturno, só em casos excepcionais, em Escolas Primárias; nestes casos, o período de funcionamento será previamente estabelecido pelo Secretário de Educação e Cultura.

$\S 2^{\circ}$ - Às escolas primárias poderão manter cursos supletivos para adolescentes de 12 a 14 anos, em horário vespertino.

\section{Título VI-Do Professor}

Capítulo I - Normas Gerais

Art. $49^{\circ}$ - A forma profissional de professor far-se-á, nos Centros de Formação do Magistério e nas Escolas Normais Regionais.

Art. $50^{\circ}$ - As Escolas Normais Regionais deverão preencher os seguintes requisitos:

a) ter preparado pelo menos 90 professores nos últimos três anos;

b) apresentarem seus professores as condições previstas, no artigo;

c) prédio próprio, com instalação adequada e Escola de Aplicação.

$\S$ Único - Os prédios, onde funcionam as Escolas Normais Regionais, que não satisfizerem às condições mencionadas neste artigo serão destinadas a outras instituições de ensino, de preferência Cursos Complementares. 
Art. $51^{\circ}$ - Enquanto se mostrar insuficiente o número de professores titulados, promoverá o Governo do Estado à nomeação de todos os concluintes de Curso Pedagógico ou Normal, logo após a sua nomeação.

Art. $52^{\circ}$ - Ficam obrigados a prestar cinco anos de serviço no magistério primário os professores que tenham recebido bolsas de estudos do Estado; a obrigação se reduz a três anos nos demais cursos.

Art. $53^{\circ}$ - Os professores formados por cada um dos Centros de Formação do Magistério serão nomeados para a Região a que o Centro pertencer, podendo prestar serviços noutra região somente os que forem aprovados em concurso, instituído para este fim.

Art. $54^{\circ}$ - Para efeito de distribuição e transferência dos professores primários, - Estado dividirá em zonas as Regiões mencionadas no artigo anterior. Os professores, após a sua nomeação, ficarão obrigados a prestar serviço durante dois anos, nas zonas mais afastadas do Centro ou da Escola Normal em que se diplomaram, e durante um ano, na zona intermediária.

$\S$ Único - Dentro da zona para que foram designados, terão os professores o direito de escolher a localidade e a escola, atendida a ordem de classificação escolar por ele atendida.

Art. $55^{\circ}$ - Será levantado, periodicamente, o número de professores de que necessitarem cada região e cada zona, a fim de ser a estes oferecidos nos Centros de Formação do Magistério e nas Escolas Normais, o número correspondente dos lugares.

Art. $56^{\circ}$ - Para receber bolsa de estudo assumirá o candidato o compromisso de prestar serviços, pelo menos durante cinco anos, em localidade carente de professores, no interesse da qual a bolsa é concedida.

$\S$ Único - Os alunos que, na data da publicação deste Decreto, estiverem matriculados no $2^{\circ}$ ciclo dos Centros de Formação do Magistério, serão dispensados da exigência contida neste artigo.

Art. $57^{\circ}-\bigcirc$ contrato de professores leigos, permitido somente na medida em que for deficiente o número dos titulados, terá vigência de um ano, podendo ser renovado.

$\S 1^{\circ}$ - Só será contratado o professor aprovado em curso de emergência ou em prova de seleção, organizados pela Secretaria de Educação e Cultura. 
$\S 2^{\circ}$ - As mesmas condições se impõe aos atuais professores leigos para permanecerem no exercício de suas funções.

Art. $58^{\circ}$ - As transferências e remoções de professores se farão a seu pedido, e segundo o critério da eficiência profissional e do tempo de serviço na zona em que se encontrem.

Art. $59^{\circ}$ - Fixará o Estado a compensão financeira a ser distribuída aos professores das zonas mais remotas, e aos que dispenderem alojamento mais da metade de seus vencimentos.

Art. $60^{\circ}$ - $\bigcirc$ cargo de Diretor da Escola Primária será exercido por professor diplomado, que preencha as seguintes condições:

a) ter sido classificado em curso de formação de Diretor;

b) prática de educação primária durante pelo menos cinco anos;

c) estágio mínimo de um ano, em estabelecimento de ensino primário.

Art. $61^{\circ}$ - A nomeação de Diretor de escola primária terá a vigência de um ano, podendo este prazo ser renovado.

Art. $62^{\circ}$ - Caberá ao Diretor da escola primária, além das funções estreitas de administração, exercer, com espírito, cooperativo, a supervisão, coordenação e ajuda profissional em relação ao trabalho dos professores e de outros funcionários da escola.

Art. $63^{\circ}$ - Para efeito da nomeação, estão sujeitos os Diretores, do mesmo modo que os professores, ao critério de zoneamento estabelecido no artigo 55.

Art. $64^{\circ}$ - Só serão nomeados Orientadores e Professores Primários que satisfizerem as seguintes condições:

a) exercício de pelo menos cinco anos de magistério;

b) curso de formação de Orientadores realizado pela Secretaria de Educação e Cultura com a duração de um ano, seguido ou não, ou outro equivalente, organizado sob os auspícios do Instituto Nacional de Estudos Pedagógicos; c) um ano de estágio bem sucedido.

Art. $65^{\circ}$ - Só poderão inscrever-se no Curso de Orientadores os candidatos que se destinem a municípios deles carentes.

Art. $66^{\circ}$ - Os professores primários que, após dois anos de exercício do magistério, se distinguirem pela sua capacidade e eficiência, serão designados para 
as escolas ou classes de aplicação, valendo a designação como título de merecimento na sua carreira.

Capítulo II - Da Formação do Professor

Art. $67^{\circ}$ - $\bigcirc$ COPE investigará, de forma permanente, as condições de formação do professor e os problemas ligados ao exercício de suas funções, particularmente no que respeita à eficiência profissional e aos meios de assegurá-la.

$\S 1^{\circ}$ - Com esse objetivo, acompanhará o COPE o trabalho dos professores e estará sempre articulando aos Centros Educacionais de Formação do Magistério.

$\S 2^{\circ}$ - Os Centros Educacionais de Formação do Magistério deverão adaptar, constantemente, o seu currículo e planos de trabalho aos resultados de pesquisa e às informações do COPE.

Art. $68^{\circ}$ - De acordo com a Lei $n^{\circ} 2.171$, de 6 de dezembro de 1957, as disciplinas integrantes do currículo de cultura geral complementares ao curso de ginásio, constituem um ano propedêutico, cuja a organização será regulamentada em Decreto especial.

Art. $69^{\circ}$ - Os cursos profissionais de formação de professores primários serão:

a) $\bigcirc$ Curso de Treinamento, de um ano.

b) $\bigcirc$ Curso Pedagógico, de dois anos.

Art. $70^{\circ}$ - $\bigcirc$ Curso de Treinamento proporcionará o mínimo de formação cultural indispensável ao exercício do magistério e terá um caráter especialmente profissional.

Parágrafo Único - As matérias básicas do Curso mencionado neste artigo serão; Português, Matemática, Estudos Brasileiros, Ciências Físicas e Naturais, Higiene Escolar, Recreação, Música e Artes Aplicadas.

Art. $71^{\circ}-\bigcirc$ Curso Pedagógico associará, de forma mais articulada e objetiva, o estudo dos fundamentos da educação e a habilitação prática para o exercício do Magistério.

Art. $72^{\circ}-\bigcirc$ Currículo do Curso Pedagógico será constituído das seguintes disciplinas: Fundamentos da Educação; Ensino de Linguagem, de Matemática, de Estudos Sociais, de Ciências Naturais, de Recreação e Jogos, de Música 
e Artes Aplicadas, atendendo-se todas essas disciplinas em ordem ao aprendizado primário.

Art. $73^{\circ}$ - Os Fundamentos da Educação compreendem os problemas de natureza e fins de educação, de integração social, de desenvolvimento da criança e das condições de aprendizagem.

Art. $74^{\circ}$ - A formação profissional dos professores se apoiará na observação do trabalho de classes, na prática de ensino em escalas ou classes de aplicação, especialmente escolhidas, e nos estudos dos programas de ensino e dos métodos mais adequados à sua execução.

Art. $75^{\circ}$ - Na organização do currículo, ter-se- á em vista que;

a) o aluno não poderá estudar mais de 6 disciplinas de cada vez;

b) o ensino se fundará no estudo de problemas, nos quais trabalharão os professores, quanto possível, de forma cooperativa e integrada.

Parágrafo Único - Tendo em vista o disposto no item b, deste Artigo, os programas devem ser elaborados e periodicamente e reexaminados pelos professores em conjunto.

Art. $76^{\circ}$ - Mediante o conhecimento dos Fundamentos da Educação e Estudos Sociais, deverão os futuros professores tornar-se capazes de introduzir os seus alunos no conhecimento do meio, da estrutura e mecanismo das instalações sociais mais ligadas à vida comum, das condições de vida do aluno e de sua família.

Art. $77^{\circ}$ - Os professores dos Cursos Profissionais dos Centros Educacionais, acima referidos, serão obrigados a um número de 18 horas de trabalho semanal, nas quais se inclui a assistência individual aos alunos e acompanhamento de trabalho destes nas classes de aplicação.

Art. $78^{\circ}$ - Os professores dos Cursos de Treinamento e do Curso Pedagógico deverão ter experiência de ensino primário de, pelo menos, cinco anos, e cursos especiais de disciplinas que pretendam lecionar.

$\S 1^{\circ}$ - Estão incluídos na categoria prevista no item b deste artigo os Cursos de Faculdade de Filosofia e outros Cursos e Estágios realizados sob auspícios do Instituto Nacional de Estudos Pedagógicos.

$\S 2^{\circ}$ - Poderá substituir as exigências do exercício de magistério primário, um exame de habilitação que demonstre conhecimentos dos problemas práticos 
de ensino primário, e a prova de haver exercido durante cinco anos o ensino secundário.

Art. $79^{\circ}$ - Os Centros Educacionais de Formação de Magistério ministrarão os seguintes cursos, além dos que foram mencionados no artigo.

a) Curso de emergência para professores leigos, de preferência com o Curso Ginasial, realizados em época sucessivas de férias, até que se complete o período de dois anos; e para o candidato que tenham curso ginasial, durante um ano contínuo, em regime de trabalho intensivo.

b) Curso de Orientador de Ensino.

c) Curso de Administração Escolar, destinados particularmente aos Diretores.

d) Curso de Extensão.

e) Curso de Aperfeiçoamento do Professor Primário.

Art. $80^{\circ}$ - São condições para ingresso no Curso Pedagógico:

a) ter Curso Ginasial;

b) ser considerado apto para o magistério primário.

Parágrafo Único - Será estabelecido, em estatuto próprio o critério para aferi283 ção dessa capacidade.

\section{Referência}

RIO GRANDE DO NORTE. Regulamento do Ensino Primário e Normal do Estado do Rio Grande do Norte. Aprovado pelo Decreto n 3.590, de $1^{\circ}$ de fevereiro de 1960. (Regulamento datilografado sob a guarda do Arquivo Público do Rio Grande do Norte, caixa 77). 